\title{
Indo-Pacific bottlenose dolphin (Tursiops aduncus) habitat preference in a heterogeneous, urban, coastal environment
}

\author{
Nardi Cribb ${ }^{1 *}$, Cara Miller ${ }^{1,2,3}$ and Laurent Seuront ${ }^{1,4,5}$
}

\begin{abstract}
Background: Limited information is available regarding the habitat preference of the Indo-Pacific bottlenose dolphin (Tursiops aduncus) in South Australian estuarine environments. The need to overcome this paucity of information is crucial for management and conservation initiatives. This preliminary study investigates the space-time patterns of habitat preference by the Indo-Pacific bottlenose dolphin in the Port Adelaide River-Barker Inlet estuary, a South Australian, urbanised, coastal environment. More specifically, the study aim was to identify a potential preference between bare sand substrate and seagrass beds, the two habitat types present in this environment, through the resighting frequency of recognisable individual dolphins.

Results: Photo-identification surveys covering the $118 \mathrm{~km}^{2}$ sanctuary area were conducted over 2 survey periods May to August 2006 and from March 2009 to February 2010. Sighting frequency of recognisable individual Indo-Pacific bottlenose dolphins established a significant preference for the bare sand habitat. More specifically, 72 and $18 \%$ of the individuals sighted at least on two occasions were observed in the bare sand and seagrass habitats respectively. This trend was consistently observed at both seasonal and annual scales, suggesting a consistency in the distinct use of these two habitats.
\end{abstract}

Conclusions: It is anticipated that these results will benefit the further development of management and conservation strategies.

Keywords: Bottlenose dolphin, Conservation, estuaries, Photo-identification, Management, Habitat type

\section{Background}

Cetacean habitats are typically heterogeneous, comprising a mosaic of patches which differ in their biological and physical properties [1]. Understanding the space-time movement patterns and distribution of organisms within their environments can provide insight into the preference of specific areas [1]; information considered essential in the development of management and conservation initiatives [2]. In this context, bottlenose dolphins (Tursiops spp.) are no exception. They occur globally in both temperate and tropical waters [3,4], and are common in coastal waters, in particular estuaries, over a wide range of habitat types, such as seagrass beds, sandy substrates and reefs [5-8]. The occurrence of bottlenose dolphins in different habitats

\footnotetext{
* Correspondence: nardi.cribb@flinders.edu.au

${ }^{1}$ School of Biological Sciences, Flinders University, Box 2100, Adelaide, SA 2001, Australia

Full list of author information is available at the end of the article
}

illustrates the ecological plasticity and adaptability of this species $[2,9-11]$. This highlights the need to understand at the individual and population level the key habitat types and locations they preferentially frequent [12]. This is especially critical for populations frequenting coastal environments, which are increasingly impacted by anthropogenic activities, such as tourism, chemical and noise pollution, habitat degradation, commercial and recreational fisheries and aquaculture [13-19], thus making them more susceptible to threats $[20,21]$.

The Indo-Pacific bottlenose dolphin (Tursiops aduncus) is a prime example of a coastal dolphin species with many populations throughout the Indo-Pacific region [22], and more specifically Australia, where they are found in a range of coastal environments such as bays, gulfs, lagoons and estuaries that are often highly urbanised $[8,16,23,24]$. However, little is still known about this species habitat preference in estuarine locations [16]. 
In South Australian waters, T. aduncus is a known resident, especially in the Port Adelaide River - Barker Inlet estuary, where animals have been recorded year-round over the past 18 years [25]. This area supports a small population of approximately 30 resident individuals as well as visiting non-regular transient animals $[25,26]$. Field observations indicate no other marine mammals, specifically delphinids, living in direct sympatry with this population. Fur seals and sea lions were, however, punctually observed hauled out within the study site. The Port Adelaide River - Barker Inlet estuary is situated in close vicinity to the city of Adelaide, hence it is highly urbanised and subjected to a variety of anthropogenic activities such as industrial and sewage pollution, recreational and commercial vessel traffic, dredging, urban development and habitat degradation [19,27-31]. As a result this area was proclaimed the Adelaide Dolphin Sanctuary (ADS) in 2005 in order to protect both the resident dolphins and their habitat [32].

Baseline habitat information is, however, still scarce and limited to the presence of bottlenose dolphins being independent of environmental features [8]. This potentially limits the development and implementation of effective conservation and management strategies, hence the long term-survival of this population. This also stresses the need to further understand and monitor the preference of habitats within this area at both the seasonal and annual scales, and to identify potential areas of high occurrence of specific individuals. In this context, the objective of this paper was to use photo-identification to assess whether recognisable individuals were consistently sighted in the same benthic habitat type at both seasonal and annual scales.

\section{Methods}

Study site

The ADS is situated in the north-eastern region of Gulf St Vincent (GSV), South Australia (Figure 1), located $15 \mathrm{~km}$ northwest of Adelaide. This area is characterised by high biodiversity and has both considerable commercial fisheries value and biological significance [33]. The sanctuary area which includes the Port Adelaide River - Barker Inlet estuary and the coastal waters extending northwards out into GSV covers an area of $118 \mathrm{~km}^{2}$. In the absence of a map of the benthic habitat in the ADS, we conducted a preliminary sampling survey to assess the nature of the benthic habitat, which showed that the ADS supports two main benthic habitat types that may be used by dolphins (Figure 1). The northern part of the sanctuary extending into the open, unsheltered waters of Gulf St Vincent is characterised by the presence of seagrass beds (predominantly Posidonia, Zostera and Heterozostera sp.; [30,34]. No seasonal fluctuations in seagrass coverage were observed. In contrast, the southern area of the sanctuary consists of shallow sheltered estuarine waters and narrow channels, bordered by mangrove forest, which are essentially devoid of vegetation such as seagrass and attached algae and consist predominantly of bare sand [35]. There is a distinct separation between these two habitat types from the mouth of the estuary out into gulf waters due to the presence of a seasonal sand bars, which constantly change the dynamics of the environment. Water depths in both habitat types range from 0.5 to $6 \mathrm{~m}$, they increase in depth ranging from 10 to $17 \mathrm{~m}$ in the dredged shipping channel of the Port Adelaide River.

\section{Data collection}

Photo-identification data from the ADS were collected between the 5 May and 30 August 2006 and 6 March 2009 to 6 February 2010 (Table 1) following the same methodology. Survey transects were designed to provide both even and representative coverage of the sanctuary and the two benthic environment types found here. Specifically, four transects were used to survey the area (Figure 1). Surveys were always conducted at steady speed of 12 knots aboard either a $6 \mathrm{~m}$ rigid-hulled inflatable vessel powered by a $70 \mathrm{HP}$ outboard engine, or a $5 \mathrm{~m}$ vessel powered by $70 \mathrm{HP}$ outboard motor and were carried out at a Beaufort Sea state of less than 3, under daylight conditions, between 7:30 am and 3:00 pm and fluctuating tidal conditions. Whilst on transect a constant watch for dolphins was maintained by two observers who scanned the water with the naked eye ahead and to $90^{\circ}$ either side of the transects. As boat access was limited in the estuary due the presence of exposed intertidal mud flats not accessible by dolphins and seasonal sand bars, sighting visibility was restricted to $200 \mathrm{~m}$ either side of the transect. Upon sighting an individual or group of dolphins (i.e. all animals within a $100 \mathrm{~m}$ radius of each other; [12]) the survey effort was ceased to record the time of the sighting and the number of dolphins present. The vessel was then moved as close to the location of the initial sighting as possible to determine the benthic environment type and record the GPS location. Benthic environment type was determined by visual analysis, as the bottom was visible due to the shallow nature and good water clarity. Note that in waters deeper than 10 $\mathrm{m}$ the bottom was not visible from the surface. Specifically in the dredged shipping channels of the Port Adelaide River, preliminary benthic sampling consistently showed the benthos to be devoid of vegetation. The benthic environment type was therefore defined within the study area by the presence of seagrass or bare sand. Once the benthic environmental data was recorded the vessel approached the individual or group and it was then endeavoured to photograph as many of the dorsal fins of the animals present as possible [36,37]. A Canon EOS 350D digital SLR with a 75-300 zoom lens was used to take all photographs. Encounters (i.e. an interaction with an individual 


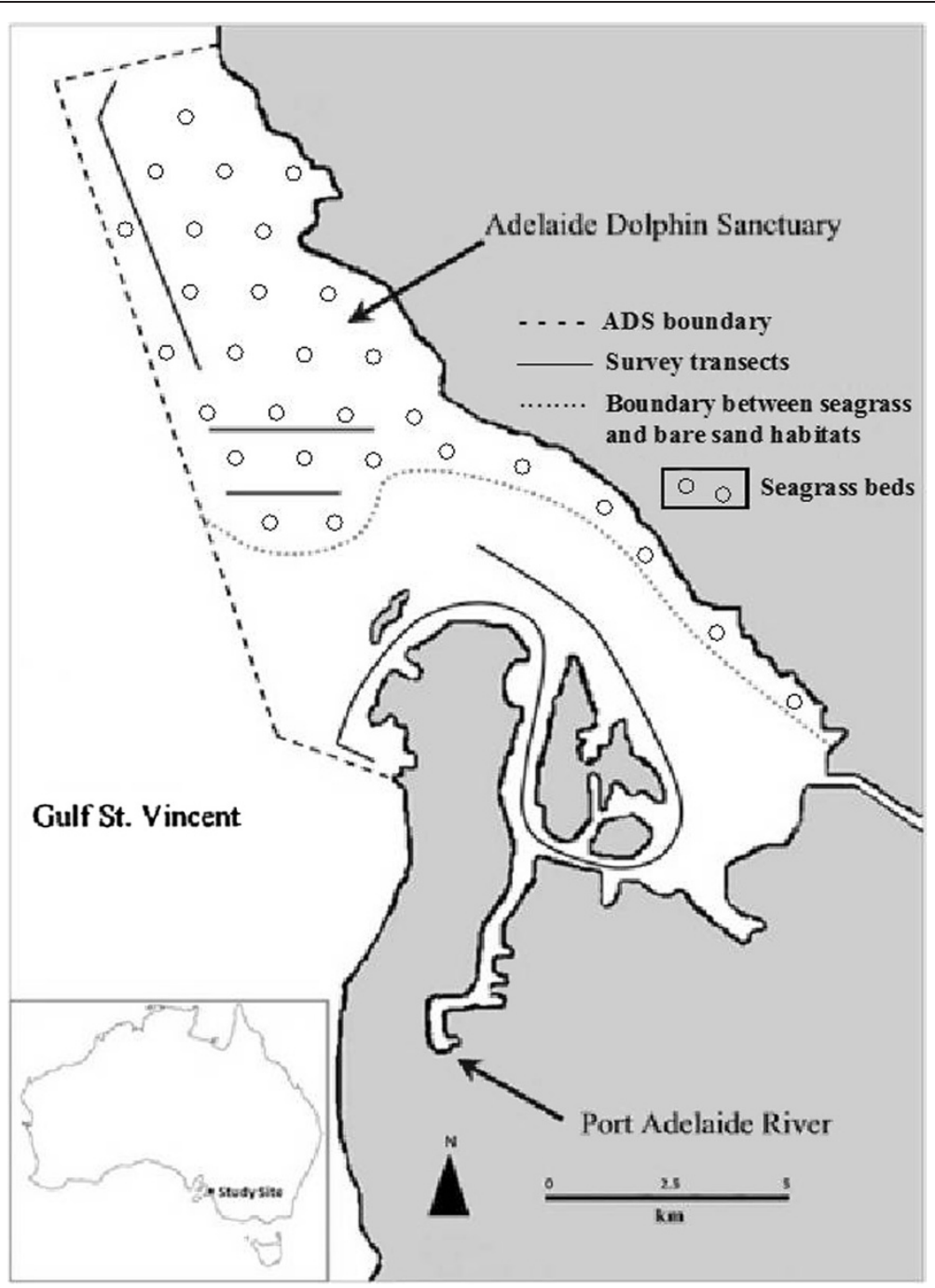

Figure 1 Map of the study area showing the locations of the survey transects (solid black lines), the sanctuary boundaries (dashed line) and the separation between the two benthic habitats (seagrass bed to the North and bare sand to South of the dotted line) in the Adelaide Dolphin Sanctuary, South Australia.

or dolphin group; [12]) were restricted to a maximum period of 20 minutes in order to attempt to minimise disturbance to the group or until all individuals in the group were photographed. The vessel then returned to the transect and continued until the transect was completed or all of the study area had been surveyed.

Table 1 Number of survey days shown as a function of both season and photo-identification survey periods

\begin{tabular}{lcc}
\hline Season & \multicolumn{2}{c}{ Photo-Identification Survey Periods } \\
\cline { 2 - 3 } & Survey Period 2006 & Survey Period 2009 - 2010 \\
\hline Spring & 1 & 4 \\
Summer & 2 & 5 \\
Autumn & 3 & 6 \\
Winter & 4 & 8 \\
\hline
\end{tabular}

\section{Photo-identification analysis}

Photo-identification of bottlenose dolphins relies on the matching of distinctive dorsal fin features, such as nicks and notches present on both the trailing and leading edges of the fin, and tip [36,37]. Photographs were assessed for photographic quality (e.g. focus, clarity, contrast, angle, portion of the fin visible and the percentage of picture filled by the fin) and graded according to quality (excellent, average, poor) using Adobe Photoshop Elements 5.0 imaging software. Only those photographs considered to be of excellent quality were included in the analysis. Poor quality photographs were always discarded from the analysis. Photographs were checked systematically against each other to develop a master catalogue of recognisable individuals and to determine the number of re-sights. The individuals not matched with animals previously recorded 
were given a unique identification number and added to the catalogue.

\section{Data analysis}

The statistical package PWAS for Windows, version 18, was used for all statistical analysis. As the data failed to meet the assumptions of normality (Kolmgorov-Smirnov test, $\mathrm{p}<0.05$ ), non-parametric tests were therefore used to make comparisons between data sets. In order to explore the habitat preference of bottlenose dolphins in the ADS the resighting frequency of individuals (i.e. the sighting frequency of recognisable individuals seen at least on two or more occasions) was estimated for each benthic habitat type. Resighting frequencies were also assessed to identify potential habitat preference between seasons, defined as spring (September - November), summer (December - February), autumn (March - May) and winter (June - August), and years. Additionally, the resighting frequencies were examined to identify habitat preferences on an individual level. Sighting frequencies between habitats were compared using the $x^{2}$ test [38]. Specifically, our survey equally covered the two habitat types; hence we compared the observed habitat preference frequencies to theoretical frequencies $(50 \%-50 \%)$.

\section{Results}

\section{Survey and photo-identification effort}

Twenty two survey days were completed during the two study periods (Table 1). An individual or group of dolphins were sighted on 126 occasions, which resulted in a total of 1602 photographs, and 502 of excellent quality used in the analysis. Although surveys were conducted on different tidal regimes, no effect of tide on the frequency of dolphin occurrence was ever observed. Note, however, that the microtidal regime [39] of the Adelaide Dolphin Sanctuary (and more generally in
South Australian gulfs) is unlikely to affect the dynamics of bottlenose dolphins in contrast to megatidal areas such as Aberdeen harbour [40]. A total of 75 distinct individuals were identified based on permanent dorsal fin markings ranging from tip nicks to trailing and leading edge notches. The 75 distinct individuals photographed during the study were sighted between 1 and 8 times. Forty nine of these individuals $(65.3 \%)$ were sighted on only one occasion. In contrast, 21 (28\%) individuals were sighted on two or three occasions and only $5(6.7 \%)$ were sighted on 4 or more occasions (Figure 2 ).

\section{Habitat preference}

The survey effort equally covered the two habitat types. Bottlenose dolphins were observed throughout the study area over both habitat types. However, the majority of sightings (i.e. $76 \%, \mathrm{n}=96$ ) was concentrated in the bare sand habitat ( $\mathrm{x}^{2}$ test, $\mathrm{df}=1, \mathrm{p}<0.05$; Figure $3 \mathrm{~A}$ ). A clear seasonal (Figure 3B) and inter-annual (Figure 3C) preference for one of the two habitat types was also observed, with individuals consistently sighted in the bare sand habitat over the four seasons. However, seagrass preference increased from 0 and $10 \%$ in winter and spring to 27 and $34 \%$ summer and autumn (Figure 3B). The preference for the bare sand habitat was consistent throughout the 3 years of the study (Figure 3C), suggesting that bare sand is the preferred habitat type used by bottlenose dolphins in this area.

\section{Individual habitat preference}

Recognisable individuals sighted in the ADS on two or more occasions showed a preference for habitat type. Twenty six dolphins were sighted on 2 or more occasions, and 18 of them (69\%) were consistently resighted in the same habitat over time. Only 8 individuals (31\%) were sighted both over bare sand and seagrass beds

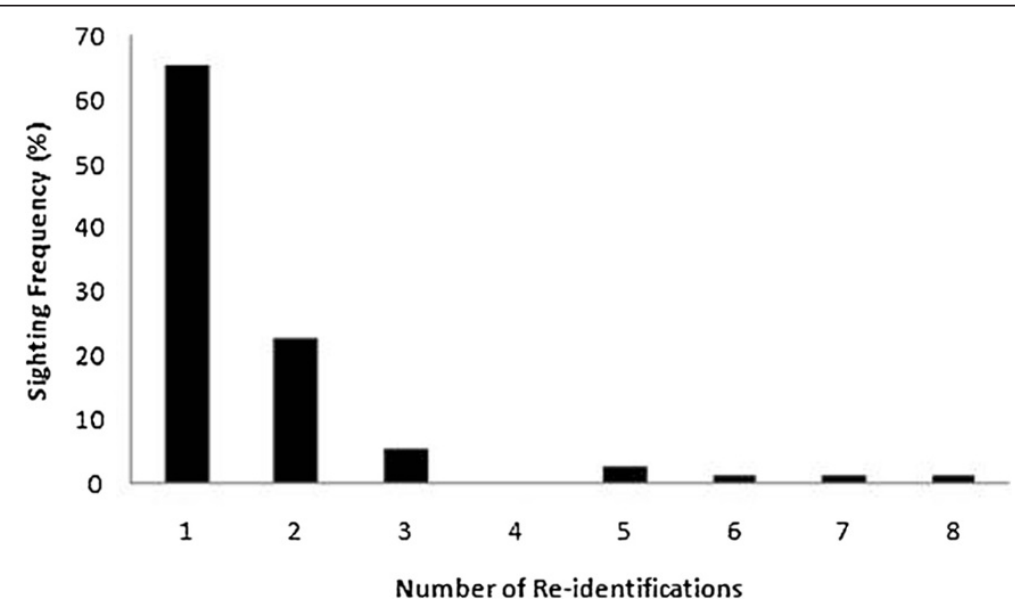

Figure 2 Sighting frequencies for individual dolphins identified in the Adelaide Dolphin Sanctuary in 2006 and between 2009 and 2010. 


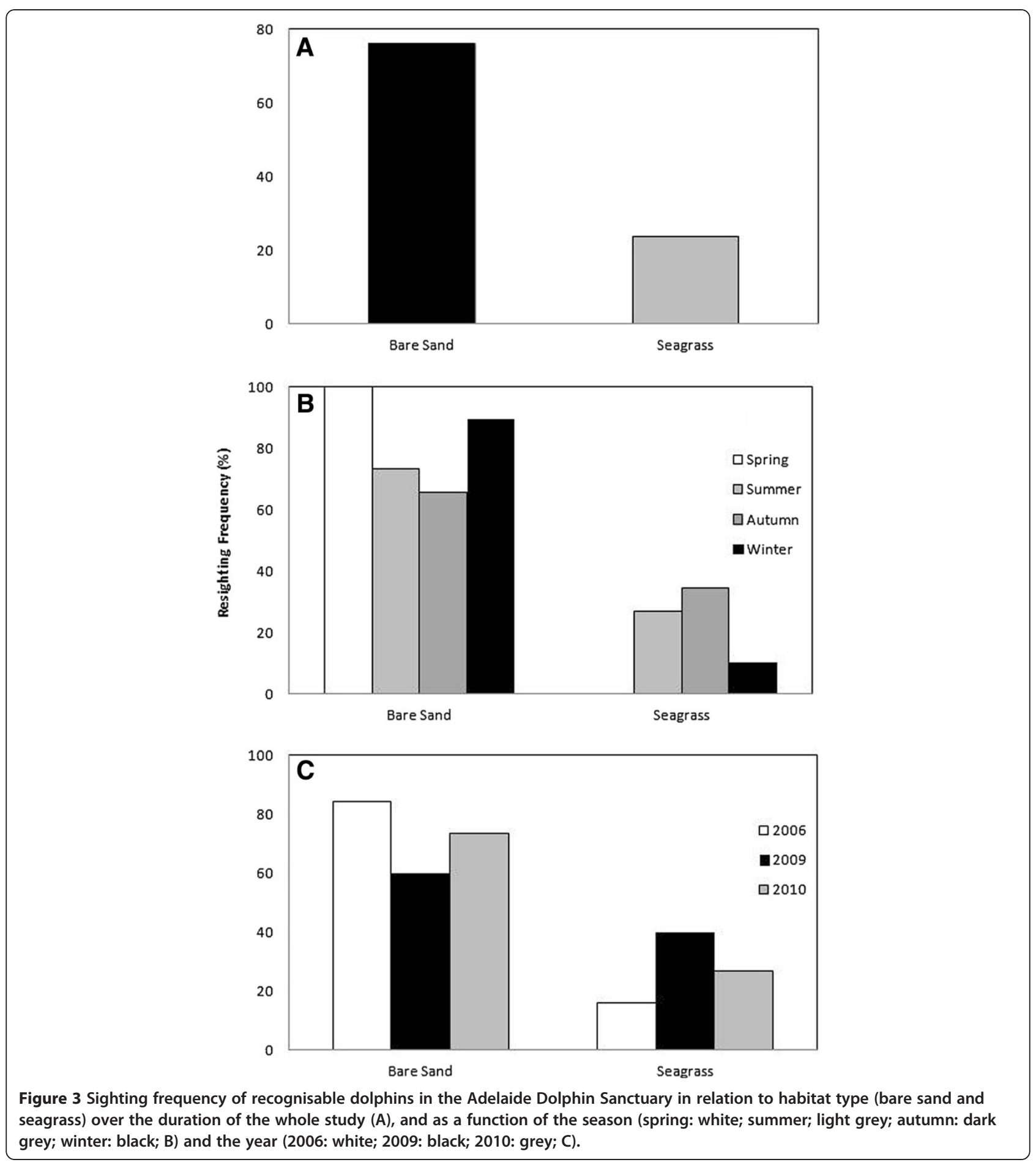

(Figure 4A). Additionally, from the 18 animals consistently sighted in the same habitat, $13(72.2 \%)$ and 5 $(27.8 \%)$ were respectively predominantly $\left(x^{2}\right.$ test, $\mathrm{df}=1$, $\mathrm{p}<0.05)$ resighted in the bare sand and seagrass habitats over time (Figure 4B).

\section{Discussion}

Indo-Pacific bottlenose dolphin habitat preference in the ADS

Our observations of dolphin presence and significantly higher sighting frequency in the bare sand habitat (76\%; 


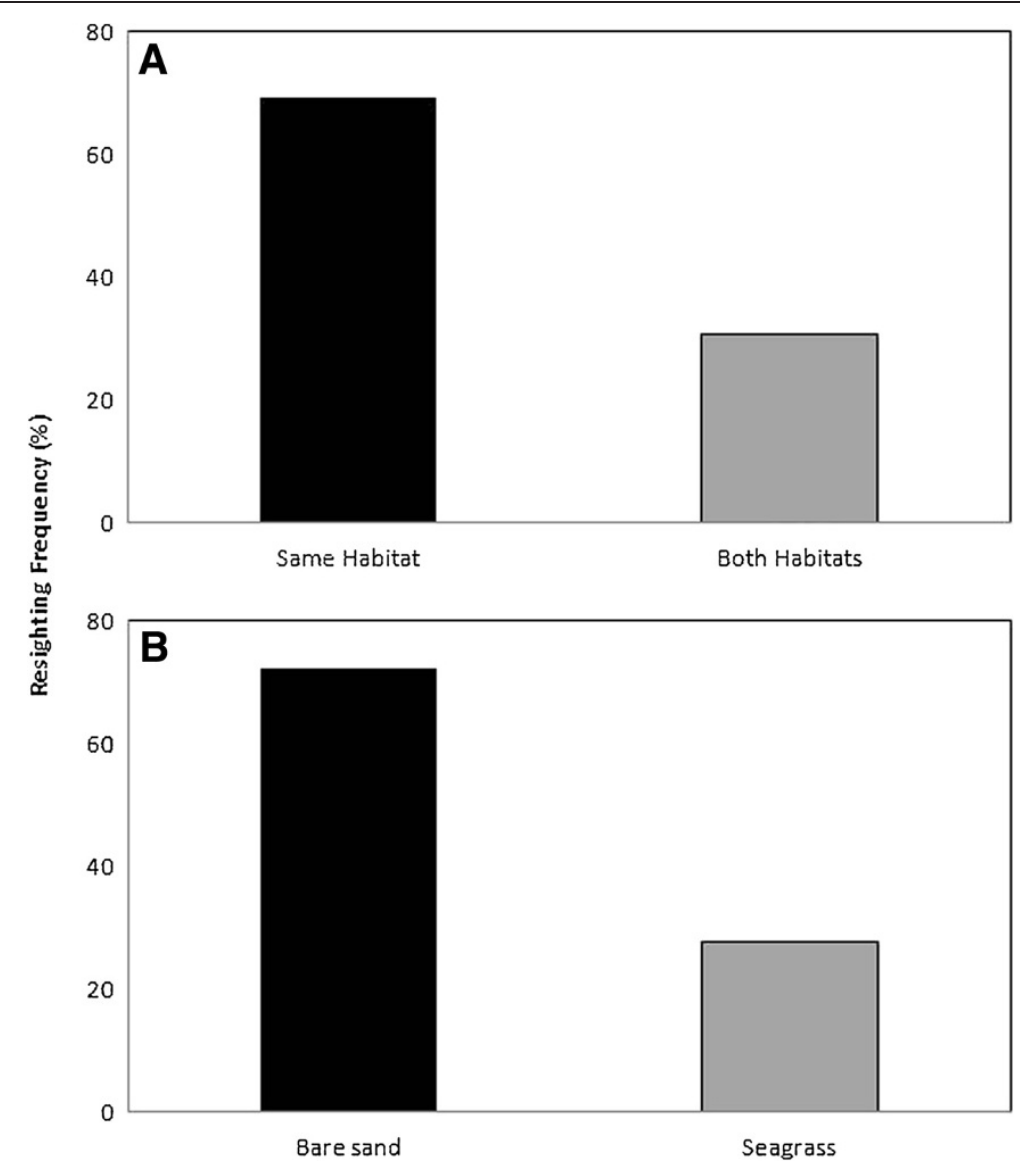

Figure 4 Resighting frequency of (A) individuals consistently sighted in the same habitat or sighted in both habitat types, and (B) only sighted in the same habitat as a function of habitat type.

Figure 3A) at both the seasonal and annual scales (Figure 3B,C) and the significantly higher resighting frequency in the same habitat (69\%; Figure 4A) are consistent with the previously reported regular occurrence and preference of bottlenose dolphins in one habitat over another $[1,6,7,41,42]$. While further work is needed to specifically address this issue, our results suggest the presence of a seasonal pattern in habitat preference with an increase in dolphin frequency in the seagrass habitat in autumn and summer (Figure 3B). Seasonal shifts and variations in habitat preference by bottlenose dolphins have also been observed in other locations such as the San Luis Pass (Texas, USA; [43]), the Moray Firth (Scotland; [9]) and the Hauraki Gulf (New Zealand; [44]). However, the occurrence of nearly one-third of the individuals (31\%; Figure 4A) over both the bare sand and the seagrass habitats may indicate that a nonnegligible proportion of the T. aduncus occurring in the ADS have enough behavioural flexibility to use the seagrass beds found in the open waters of Gulf St. Vincent as well as the sheltered waters found in the inner estuarine part of the ADS (Figure 1). More specifically, respectively 72 and $28 \%$ of the resighted individuals were observed over the bare sand and the seagrass habitats (Figure 4B). This suggests that the bare sand habitat may be a core area for this population, in contrast to previous work stressing the vital role of seagrass beds for bottlenose dolphins [41,42]. However, further investigation into the behavioural budget of this population is needed to determine how and why these habitats differ in their importance and use.

\section{Estuaries as important dolphin habitats}

Our observations of higher dolphin frequency in the bare sand habitat of the Adelaide Dolphin Sanctuary (ADS) further support the importance of estuarine waters for this species $[12,16,45-49]$. This may be linked to the overall nature of estuaries and their potential for high productivity and prey abundances [50]. Bare sand substrates may also provide a less complex habitat than seagrass in which to feed, particularly as seagrass beds impair their ability to echolocate to find prey [51]. In addition,, the consistent high occurrence of individuals at the seasonal and annual scales in the shallow and sheltered waters of the bare sand 
habitat (Figure 3B,C) may also be related to threat avoidance, as bottlenose dolphin habitat preference is influenced by shark predation [52]. Specifically, in South Australian waters, dolphins are considered the primary prey of white sharks [53]. Although occasional, the white shark (Carcharodon carcharias) and the bronze whaler (Carcharodon brachyurus) both frequent the ADS [26]. Despite the relatively low occurrence of sharks in the ADS compared to other locations such as Sarasota (Florida), Moreton Bay (Queensland) and Shark Bay (Western Australia) [26,54-56], one dolphin observed during the study had, a large healed scar on the leading edge of its dorsal fin (Figure 5A). This scar is likely the result of a shark and not other sources such as boat strike, entanglement or other dolphins due to its distinct crescent-shape which contrasts with the deeper penetrating laceration caused by boat strikes and entanglements (Figure 5B), [56]. This suggests that predation may be a potential influencing factor for the high frequency of dolphin sightings in shallow and sheltered waters characterising the bare sand habitat. The bare sand habitat may hence provide a suitable haven from predators, in contrast to the open environment characterising the seagrass habitat.

\section{On the influence of sex and social structure on habitat preference}

The frequency of the same individuals within the same habitat over time (Figure 4) may be linked to other factors such as social organisation and association patterns [40]. Specifically, bottlenose dolphin habitat preference has been explained by the home range of individuals and the social strategies which individuals or different sexes adopt $[1,57]$. It has been suggested that protected, shallow and narrow waterways which are geographically further from the open ocean such as the bare sand environment in the present work (see Figure 1), generally promote limited movement patterns and therefore some degree of site fidelity $[47,58]$. In contrast, individuals found in open habitats have more extensive home ranges and a lesser degree of site fidelity $[47,58]$. The individuals resighted consistently over time in the bare sand habitat may hence potentially represent resident individuals, and therefore those sighted on fewer occasions in the seagrass habitat may be transients. Additionally, this sighting frequency may be related to foraging or social specific strategies of male and females. Females have smaller home ranges and frequent more areas which provide a higher concentration of resources, such as estuaries that are important for reproduction and calving and the avoidance of predators $[47,59]$. In contrast, males cover wider ranges than females which has been attributed to female breeding cycles and accessibility $[45,59]$. As a consequence, the animals sighted consistently in the bare sand habitat might be females utilising local resources, whilst those sighted on fewer occasions in the seagrass may be males searching for females.

\section{Conclusion}

Our results show that bottlenose dolphins in the Adelaide Dolphin Sanctuary occur predominantly in a bare sand habitat. The consistent occurrence and resighting of individuals at both the seasonal and annual scale clearly highlight the importance of the sheltered, bare sand habitat for this population. With a paucity of information available on dolphin habitat due to a lack of monitoring and research in this area, these results provide critical information, which can improve conservation and management strategies previously implemented in the ADS [32]. Specifically, it is recommended to monitor future trends in dolphin spatial and temporal habitat preference, as initiated here through photo-identification surveys. Additionally, due to the presence and potential growth of anthropogenic activities in the vicinity of the ADS, it is critical to understand the details of the seasonal patterns of habitat preference and social activities of bottlenose dolphins that will ultimately help in objectively establishing restricted access to specific core locations of the Adelaide Dolphin Sanctuary.
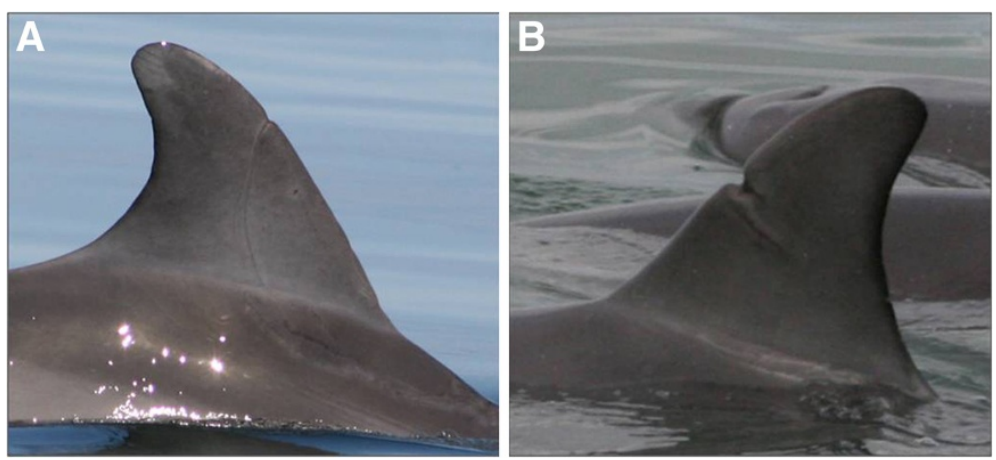

Figure 5 Examples of both natural (A) and anthropogenic (B) injuries observed on Indo-Pacific bottlenose dolphins photographed in the Adelaide Dolphin Sanctuary. Natural injuries considered to be inflicted by shark bites are crescent in shape, whilst in contrast those inflicted by anthropogenic causes (e.g. boat strike, entanglements) are usually deeper penetrating 'slash like' lacerations. 
We also stress that the approach presented here may be applicable to other anthropogenically impacted coastal environments, where the identification of dolphin habitat preferences might have critical conservation and management implications. Finally, as the driving mechanisms influencing bottlenose dolphin habitat preferences may differ depending on the intrinsic properties of their environment, such as the nature of anthropogenic activities, coastal geomorphology and bottom topography, further studies are needed to understand habitat choice on both local and global scales.

\section{Competing interests}

The authors declare that they have no competing interests.

\section{Authors' contributions}

NC and LS designed the research. NC conducted field work and data analysis and wrote the final draft of the paper. CM contributed to previous drafts of the manuscript. LS assisted with statistical analysis and data interpretation and contributed to previous drafts of the manuscript. All authors contributed to the planning and design of the study and have read and approved the final manuscript.

\begin{abstract}
Acknowledgements
Rob Laver, Verity Gibbs, Brett Williams and staff from the Department of Environment and Natural Resources are acknowledged for providing resources and support in the collection of data. Thank you to Clayton McCloud, Coraline Chapperon, Stephanie Duong, Peter Cribb, and Mike Bossley for their contribution to support in the field. We also thank William Allen for providing comment on an earlier draft of this manuscript. This research was financially supported under Australian Research Council's Discovery Projects funding scheme (projects number DP0664681 and DP0988554), Marine Innovation South Australia (MISA), the Department of Environment and Heritage and the Flinders Collaborative Research Grant Scheme (FCRGS) from the Faculty of Science and Engineering, Flinders University. Professor Seuront is the recipient of an Australian Professional Fellowship (project number DP0988554). Field work was done under ethics approval from Flinders University (Project E269).
\end{abstract}

\section{Author details}

${ }^{1}$ School of Biological Sciences, Flinders University, Box 2100, Adelaide, SA 2001, Australia. ${ }^{2}$ Faculty of Science, Technology and the Environment, University of the South Pacific, Laucala campus, Suva, Fiji. ${ }^{3}$ The Whale and Dolphin Conservation Society International, Chippenham, UK. ${ }^{4}$ South Australian Research and Development Institute, Aquatic Science, West Beach, SA 5022, Australia. ${ }^{5}$ Centre National de la Recherche Scientifique, Laboratoire d'Océanologie et de Géosciences, UMR LOG 8187, Université des Sciences and Technologies de Lille, Station Marine, Wimereux 62930, France.

Received: 13 July 2012 Accepted: 7 January 2013

Published: 1 February 2013

\section{References}

1. Ballance LT: Habitat use patterns and ranges of the bottlenose dolphin in the Gulf of California, Mexico. Marine Mammal Sci 1992, 8:262-274.

2. Bearzi G, Azzellino A, Politi E, Costa M, Bastianini M: Influence of seasonal forcing on habitat use by bottlenose dolphins Tursiops truncatus in the North Adriatic Sea. Ocean Sci J 2008, 43:175-182.

3. Leatherwood S, Reeves RR: The Sierra Club handbook of whales and dolphins. San Francisco: Sierra Club Books; 1983.

4. Connor RC, Wells RS, Mann J, Read AJ: The bottlenose Dolphin: Social Relationships in a fission-fusion society. In Cetacean Societies: Field Studies of Dolphins and Whales. Edited by Mann J, Connor RC, Tyack PL, Whitehead H. Chicago: The University of Chicago Press: 2000:1-34.

5. Hansen MT, Defran RH: The behaviour and feeding ecology of the Pacific coast bottlenose dolphin, Tursiops truncatus. Aquatic Mammals 1993, 19:127-142
6. Grigg E, Markowitz H: Habitat use by bottlenose dolphins (Tursiops truncatus) at Turneffe Atoll, Belize. Aquatic Mammals 1997, 23:163-170.

7. Allen MC, Read AJ, Gaudet J, Sayigh LS: Fine-scale habitat selection of foraging bottlenose dolphins Tursiops truncatus near Clearwater, Florida. Mar Ecol Prog Ser 2001, 222:253-264.

8. Cribb N, Miller C, Seuront L: Assessment of bottlenose dolphin (Tursiops aduncus) habitat characteristics in the estuarine waters of the Adelaide Dolphin Sanctuary, South Australia. J Mar Ani Ecol 2008, 1:1-3.

9. Wilson B, Thompson PM, Hammond PS: Habitat use by bottlenose dolphins: seasonal distribution and stratified movement patterns in the Moray Firth, Scotland. J Appl Ecol 1997, 34:1365-1374.

10. Shane $\mathrm{SH}$ : Residence patterns, group characteristics, and association patterns of bottlenose dolphins near Sanibel Island, Florida. Gulf Mexico Sci 2004, 22:1-12

11. Sargeant BL, Wirsing AJ, Heithaus MR, Mann J: Can environmental heterogeneity explain individual foraging variation in wild bottlenose dolphins (Tursiops sp.)? Behav. Ecol Soc 2007, 61:679-688.

12. Ingram SN, Rogan E: Identifying critical areas and habitat preferences of bottlenose dolphins Tursiops truncatus. Mar Ecol Prog Ser 2002, 244:247-255.

13. Watson-Capps JJ, Mann J: The effects of aquaculture on bottlenose dolphin (Tursiops sp.) ranging in Shark Bay, Western Australia. Biol Conserv 2005, 124:519-526.

14. Bedjer L, Samuels A, Whitehead H, Gales N, Mann J, Connor R, Heithaus M, Watson-Capps J, Flaherty C, Krützen M: Decline in relative abundance of bottlenose dolphins exposed to long-term disturbance. Conserv Biol 2006, 20:1791-1798.

15. Wright AJ, Soto NA, Baldwin AL, Bateson M, Beale CM, Clark C, Deak T, Edwards EF, Fernández A, Godinho A, Hatch LT, Kakuschke A, Lusseau D, Martineau D, Romero ML, Weilgart LS, Wintle BA, Notobartolo-di-Sciara G, Martin V: Do marine mammals experience stress related to anthropogenic noise? Int J Comp Psychol 2007, 20:274-316.

16. Fury CA, Harrison PL: Abundance, site fidelity and range patterns of Indo-Pacific bottlenose dolphins (Tursiops aduncus) in two Australian subtropical estuaries. Mar Freshwater Res 2008, 59:1015-1027.

17. Lukoschek V, Chilvers BL: A robust baseline for bottlenose dolphin abundance in coastal Moreton Bay: a large carnivore living in a region of escalating anthropogenic impacts. Wildl Res 2008, 35:593-605.

18. Lavery TJ, Kemper CM, Sanderson K, Schultz CG, Coyle P, Mitchell JG, Seuront L: Heavy metal toxicity of kidney and bone tissues in South Australian adult bottlenose dolphins. Mar Environ Res 2009, 67:1-7.

19. Seuront $L$, Cribb N: Fractal analysis reveals pernicious stress levels related to boat presence and type in the Indo-Pacific Bottlenose dolphin, Tursiops aduncus. Physica A 2011, 390:2333-2339.

20. Stockin KA, Lusseau D, Binedell V, Wiseman N, Orams MB: Tourism affects the behavioural budget of the common dolphin Delphinus sp. in the Hauraki Gulf, New Zealand. Mar Ecol Prog Ser 2008, 355:287-295.

21. Wright AJ, Deak T, Parsons ECM: Concerns related to chronic stress in marine mammals. Inter Whaling Commission 2009, 1-7. SC/61/E16.

22. Ross GJB: Review of the conservation status of Australia's smaller whales and dolphins. Canberra: Australian Government; 2006:124.

23. Möller LM, Allen SJ, Harcourt RG: Group characteristics, site fidelity and seasonal abundance of bottlenose dolphins Tursiops aduncus in Jervis Bay and Port Stephens, south-eastern Australia. Aust. Mammal 2002, 24:11-21.

24. Kemper CM, Harcourt R, Gibbs S, Miller C, Wright A: Estimating population size of 'at risk' bottlenose and common dolphins in Spencer Gulf and Gulf St Vincent. Canberra: South Australia. Consultancy report to Department of the Environment and Heritage; 2006.

25. Kemper CM, Bossley M, Shaughnessy P: Marine mammals of gulf St vincent and investigator straight and backstairs passage. In Natural History of Gulf St Vincent. Edited by Shepherd S, Bryars S, Kirkegaard I, Harbison P. Adelaide: Royal Society of South Australia; 2008:339-352.

26. Steiner A, Bossley M: Some reproductive parameters of an estuarine population of Indo-pacific bottlenose dolphins (Tursiops aduncus). Mar Mammal Sci 2008, 2:34-63.

27. Edyvane K: Pollution: The death knell of our mangroves? SAFISH 1991, $16: 47$

28. Edyvane K: Conserving marine biodiversity in South Australia - Part 2 Identification of high conservation value in South Australia. Final Report No 39. Adelaide, South Australia: South Australian Research and Development Institute, Department of Primary Industries and Resources; 1999:328. 
29. Edyvane K: Environmental management review of the Barker Inlet and Port Estuary Environs, Report to AGC Woodward-Clyde PTY LTD and Dames and Moore NRM; 2000:21

30. Connolly RM: A comparison of fish assemblages from seagrass and unvegetated areas of a Southern Australian estuary. Aust J Mar Freshwater Res 1994, 45:1033-1044.

31. Bryars S: An inventory of important coastal fisheries habitats in South Australia. South Australia: Fish Habitat Program, Primary Industries and Resources; 2003:1000.

32. Adelaide Dolphin Sanctuary Act; http://www.legislation.sa.gov.au/LZ/C/A/ ADELAIDE\%20DOLPHIN\%20SANCTUARY\%20ACT\%202005.aspx.

33. Tanner J, Fairhead A, Marsh R, Miller D: Environmental assessment of the dredge site at Outer Harbour: Berth 8 Option. SARDI Aquatic Sciences: Report for GHD Pty Ltd; 2003.

34. Bloomfield A, Gillanders B: Fish and invertebrate assemblages in seagrass, mangrove, saltmarsh, and nonvegetated habitats. Estuaries 2005, 28:63-77.

35. Jones GK, Baker JL, Edyvane K, Wright GJ: Nearshore fish community of the Port River-Barker Inlet Estuary, South Australia. I. Effect of thermal effluent on fish community structure, and distribution and growth of economically important fish species. Mar Freshwater Res 1996, 47:785-799.

36. Würsig $B$, Würsig M: The photographic determination of group size, composition, and stability of coastal porpoises (Tursiops truncatus). Science 1997, 198:755-756.

37. Würsig B, Jefferson TA: Methods of photo-identification for small cetaceans. In Individual Recognition of Cetaceans: Use of Photo-Identification and other Techniques to Estimate Population Parameters. Edited by Hammond PS, Mizroch SA, Donovan GP. Cambridge: Report of the International Whaling Commission, Special Issue 12; 1990.

38. Zar JH: Biostatistical Analysis. Upper Saddle River, NJ: Prentice Hall; 1996.

39. Tomczak M, Godfrey JS: Regional Oceanography: An Introduction. Oxford, GB: Pergamon; 1994

40. Sini MI, Canning SJ, Stockin KA, Pierce GJ: Bottlenose dolphins around Aberdeen harbour, north-east Scotland: a short study of habitat utilization and the potential effects of boat traffic. J Mar Biol Assoc UK 2005, 85:1547-1554.

41. Shane SH: Behaviour and ecology of the bottlenose dolphin at Sanibel Island, Florida. In The Bottlenose Dolphin. Edited by Leatherwood S, Reeves RR. San Diego: Academic; 1990:245-261.

42. Barros N, Wells RS: Prey and feeding patterns of resident bottlenose dolphins (Tursiops truncatus) in Sarasota Bay, Florida. J Mammal 1998, 79:1045-1059.

43. Maze KS, Wursig B: Bottlenose dolphins of San Luis Pass, Texas: Occurrence patterns, site-fidelity, and habitat use. Aquatic Mammals 1999, 25:91-103.

44. Berghan J, Algie KD, Stockin KA, Wiseman N, Constantine R, Tezanos-Pinto G, Mourao F: A preliminary photo-identification study of bottlenose dolphin (Tursiops truncatus) in Haruaki Gulf, New Zealand. New Zeal J Mar Fresh Res 2008, 42:465-472.

45. Wells RS, Scott MD, Irvine AB: The social structure of free-ranging bottlenose dolphins. In Current Mammalogy, Volume 1. Edited by Genoways HH. New York: Plenum Press; 1987:247-305.

46. Wilson B, Hammond PS, Thompson PM: Estimating size and assessing trends in a coastal bottlenose dolphin population. Ecol Appl 1999, 9:288-300.

47. Gubbins C: Use of home ranges by resident bottlenose dolphins (Tursiops truncatus) in a South Carolina estuary. J Mammal 2002, 83:178-187.

48. Zolman ES: Residence patterns of bottlenose dolphins (Tursiops truncatus) in the Stono River estuary, Charleston County, South Carolina. U.S.A. Mar Mammal Sci 2002, 18:879-892.

49. Irwin LJ, Wursig B: A small resident community of bottlenose dolphins, Tursiops truncatus, in Texas: Monitoring recommendations. Gulf of Mexico Science 2004, 22:13-21.

50. Moyle PB, Cech JJ Jr: Fishes: An introduction to ichthyology. New Jersey: Prentice Hall Inc; 1982.

51. Nowacek DP: Acoustic ecology of foraging bottlenose dolphins (Tursiops truncatus), habitat-specific use of three sounds types. Mar Mammal Sci 2005, 21:587-602.

52. Heithaus MR, Dill LM: Food availability and tiger shark predation risk influence bottlenose dolphin habitat use. Ecology 2002, 83:480-491.
53. Bruce BD: Preliminary observations on the biology of the white shark, Carcharodon carcharias, in South Australian waters. Aust Mar Freshwater Res 1992, 43:1-11.

54. Urian KW, Wells RS, Scott MD, Irvine AD, Read AJ, Hohn AA: When the shark bites: An analysis of shark bite scars on wild bottlenose dolphins (Tursiops truncatus) from Sarasota Florida. Monaco: The World Marine Mammal Conference; 1998.

55. Corkeron PJ, Morris RJ, Bryden MM: A note on healing of large wounds in bottlenose dolphins, Tursiops truncatus. Aquatic Mammals 1987, 13:96-98.

56. Heithaus MR: Shark attacks on bottlenose dolphins (Tursiops aduncus) in Shark Bay, Western Australia: Attack rate, bite scar frequencies, and attack seasonality. Mar Mammal Sci 2001, 17:526-539.

57. Wells $R$ : The role of long term study in understanding the social structure of a bottlenose dolphin community. In Dolphin societies: discoveries and puzzles. Edited by Pryor K, Norris KS. Berkeley: University of California Press; 1991:199-225.

58. Defran $\mathrm{RH}$, Weller DW: Occurrence, distribution, site fidelity and school size of bottlenose dolphins (Tursiops truncatus) off San Diego, California. Mar Mammal Sci 1999, 15:366-380

59. Quintana-Rizzo E, Wells RS: Resighting and association patterns of bottlenose dolphins (Tursiops truncatus) in the Cedar Keys, Florida: insights into social organization. Can J Zool 2001, 79:447-456.

doi:10.1186/2046-9063-9-3

Cite this article as: Cribb et al:: Indo-Pacific bottlenose dolphin (Tursiops aduncus) habitat preference in a heterogeneous, urban, coastal environment. Aquatic Biosystems 2013 9:3.

\section{Submit your next manuscript to BioMed Central and take full advantage of:}

- Convenient online submission

- Thorough peer review

- No space constraints or color figure charges

- Immediate publication on acceptance

- Inclusion in PubMed, CAS, Scopus and Google Scholar

- Research which is freely available for redistribution

Submit your manuscript at www.biomedcentral.com/submit
C Biomed Central 